\title{
Proptosis as a manifestation of acute myeloid leukaemia
}

\author{
B. K. JHA AND P. A. LAMBA
}

Departments of Pathology and Ophthalmology, Jawaharlal Institute of Post-graduate Medical Education and Research, Pondicherry, India

Orbital or subconjunctival infiltration occurs frequently in acute and chronic lymphatic leukaemia, but only rarely in myelogenous leukaemia (Chatterjee and Sen, 1960). $\vec{N}$ Chloroma, an atypical form of myeloblastic leukaemia, often manifests itself as a localized mass in the orbital periosteum, and the proptosis produced in such cases may be the firsto sign of the disease (Goodman and Iverson, 1946). It is estimated that two-thirds of $\rightarrow$ patients with myeloid leukaemia present with some blurring of vision and accompanying fundus changes.

Although orbital infiltration in myelogenous leukaemia certainly occurs (Consul, $\frac{\mathbb{8}}{3}$ Kulshrestha, and Mehortra, I967; Crombie, I967; Reese and Guy, r933; Mortada, I963; Gupta, Agarwal, and Pratab, 1970; Mathur, Gupta, Nema, and Katiyar, 1970), it is nợ a frequent manifestation, and the two cases reported below are therefore of interest.

\section{Case reports}

Case I, a girl aged 7 years, was brought to JIPMER Hospital with a I5-day history of gradual $\stackrel{\circ}{\AA}$ and painless but progressive bilateral proptosis. There was no history of trauma, facial sepsis, or $\overrightarrow{\vec{A}}$ of any bleeding disorder or epistaxis.

\section{GENERAL EXAMINATION}

The patient was restless, looked ill, and was markedly anaemic. The pulse rate was $90 / \mathrm{min}$. and the temperature $99^{\circ} \mathrm{F}$. The cervical lymph nodes were not palpable. There was no oedema over the mastoid region and no evidence of sternal tenderness. The cardiovascular and respiratory systems were normal. The liver and spleen, which were just palpable, were smooth and soft.

oGULAR EXAMINATION (Fig. I, opposite)

Both eye lids were swollen and tense. The conjunctiva was markedly chemotic and congested. There was an irreducible axial proptosis. The globe was immobile in all directions. There was $\mathbb{N}$ evidence of the corneae, with a hypopyon ulcer on the right cornea while the left was hazy and $N$ lustreless. Details of the posterior segment could not be seen.

DIAGNOSIS

Leukaemia with bilateral proptosis. Other possibilities were bilateral orbital cellulitis, cavernous@ sinus thrombosis, and neuroblastoma, with orbital deposits. 


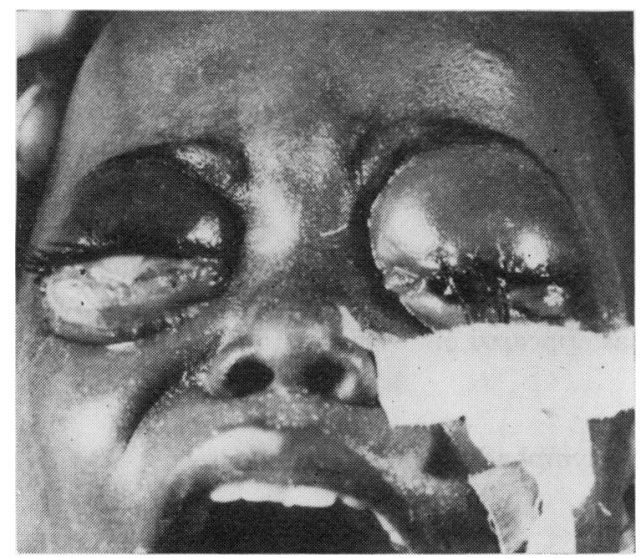

FIG. I Bilateral proptosis due to acute myelogenous leukaemia (Case I)

\section{LABORATORY INVESTIGATIONS}

The urine and stools were normal. $\mathrm{Hb} 8 \mathrm{~g} . / 100 \mathrm{ml}$.

Total white blood cells 70,000 per cu. $\mathrm{mm}$; neutrophils 12 per cent., eosinophils 2 per cent., lymphocytes 2 per cent. The peripheral blood film (Fig. 2A) showed myeloblasts 68 per cent., promyelocytes 5 per cent., and myelocytes 7 per cent.

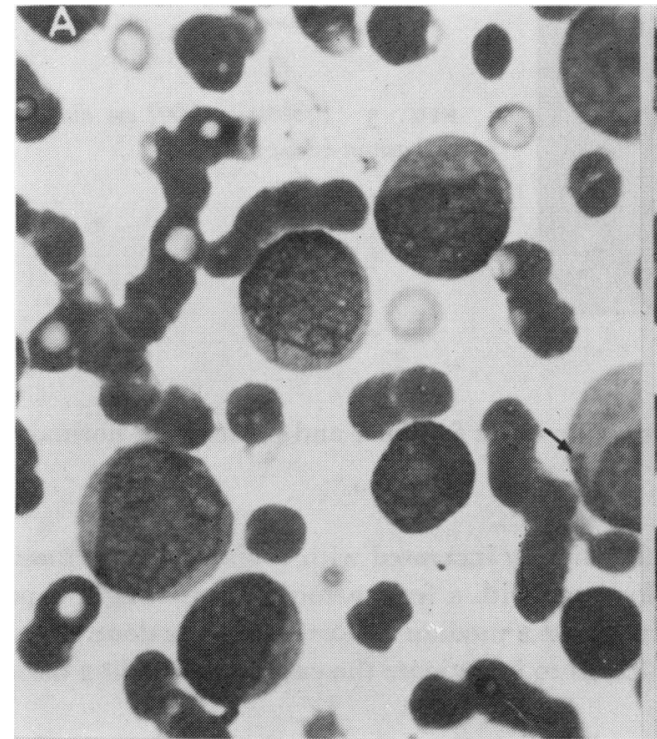

(A) Peripheral blood smear $\times 100$

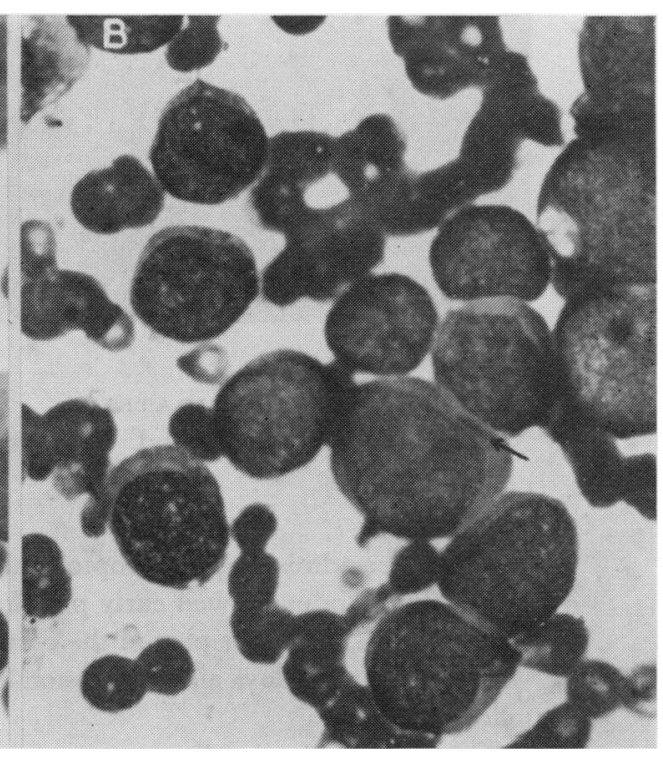

(B) Bone marrow smear $\times \mathbf{1 0 0}$

FIG. 2 A group of myeloblasts, one showing Auer bodies (arrow)

The bone marrow film (Fig. 2B) showed hypercellularity with marked depression of erythropoiesis and megakaryocytopoiesis. There was marked proliferation of myleoid cells with a large number of myeloblasts and promelocytes. Erythroid/myeloid ratio I/6o. Plasma cells $0 \cdot 1$ per cent.

Serum iron $83 \mu \mathrm{g}$. per cent. and serum uric acid $7 \cdot 3 \mathrm{mg}$. per cent.

Chest $x$ ray was normal. $X$ ray of the orbits showed soft tissue shadows on both sides. The maxillary antra were hazy. 


\section{TREATMENT}

The diagnosis of acute myeloid leukaemia with secondary orbital deposits leading to proptosis was confirmed, and the patient was given oral prednisolone $5 \mathrm{mg}$. 6-hrly with terramycin syrup and supportive therapy. Local treatment aimed to prevent exposure of the corneae, and a temporary lid suture was placed on the left side. Local antibiotics and atropine ointment were instilled.

Case 2, a 3-year-old boy, was brought to the hospital with a history of prominence of the left eye and mild intermittent fever for one week. There was no accompanying pain in the eye and no history of local trauma. No swellings has appeared elsewhere in the body.

\section{EXAMINATION}

The child did not appear to be ill. No lymphadenopathy was observed. The liver and spleen were not palpable.

\section{OGULAR EXAMINATION}

The right eye was normal. The left eye showed axial proptosis with gross limitation of all ocular movements (Fig. 3). The proptosis was not significantly reducible. There was partial dropping of the lid. No conjunctival chemosis was present. The cornea was clear and the pupil showed sluggish reaction to light. Ophthalmoscopy revealed normal fundi.

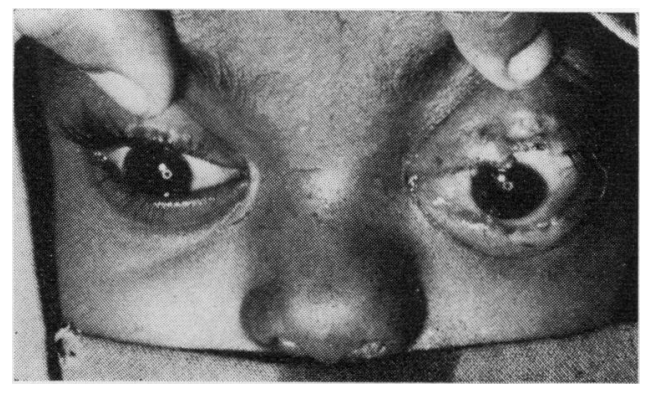

FIG. 3 Proptosis of left eye due to acute leukaemia (Case 2)

LABORATORY INVESTIGATIONS

Nothing abnormal was found. $X$ rays of the optic foramen and orbits were normal.

PROGRESS

A week after admission, the proptosis had slightly increased with conjunctival chemosis in the lower part. The fundus showed early papilloedema with a few haemorrhages. Slight exposure keratitis developed on the lower part of the cornea and a median tarsorrhaphy was done.

An epistaxis ro days after admission led us to investigate the case for a bleeding disorder, with the following results:

Total white blood cells 7,900/cu.mm., bleeding time $5 \mathrm{~min}$; clotting time $3 \mathrm{~min}$; erythrocyte sedimentation rate $100 \mathrm{~mm}$./ Ist hr (Westergren). The peripheral blood film showed myeloblasts I 4 per cent., promyelocytes 2 per cent., metamyelocytes I per cent., neutrophils 16 per cent., and lymphocytes 67 per cent.

Bone marrow biopsy showed normal cellularity. Erythropoiesis showed normoblastic depression. There was marked myeloid hyperplasia. Some promyelocytes and myeloblasts were seen. Erythroid/myeloid ratio I/I 2. Plasma cells 0.2 per cent.

DIAGNOSIS

Myeloid leukaemia. 
TREATMENT

The child was given oral prednisolone $5 \mathrm{mg}$. 6-hrly with intravenous injections of Endoxan $100 \mathrm{mg}$. biweekly, with supportive therapy.

RESULT

The patient responded favourably after 3 weeks; the proptosis was reduced with return of ocular movements.

\section{Discussion}

Proptosis in cases of leukaemia may be caused by retrobulbar haemorrhage or leukaemic deposits in the orbital cavity. Leukaemic proptosis may not always be accompanied by marked leucocytosis and premature cells in the peripheral blood smear as observed in Case 2. In such cases the diagnosis of leukaemia may be missed unless a bone marrow biopsy is performed as a routine investigation in all cases of proptosis in children (Crombie 1967), especially those of sudden onset. The incidence of proptosis in cases of lymphatic leukaemia has been reported as 2 per cent. (Reese and Guy, 1933), but it is rare in myeloid leukaemia.

Chloroma, a variant of acute myeloid leukaemia, commonly produces proptosis as a result of subperiosteal orbital infiltration (Sorsby, I95 I). Whatever the nature and colour of the deposits the incidence of chloroma is fast declining.

The proptosis in cases of leukaemia tends to be bilateral with associated conjunctival chemosis (Case I), but there was unilateral proptosis in Case 2. A sudden onset of bilateral proptosis in a child should suggest the conditions of bilateral orbital cellulitis, cavernous sinus thrombosis, acute leukaemia, or neuroblastoma with secondary orbital deposits. In the first two conditions there is usually an obvious focus of sepsis around the head and face and the patient is very toxic. Bilateral orbital cellulitis is uncommon. Neuroblastoma can be ruled out by examination for abdominal tumour. An examination of the peripheral blood film and bone marrow will reveal the presence of leukaemia.

\section{Summary}

Two cases of acute myeloid leukaemia presented with proptosis, one bilateral and one unilateral. The diagnostic difficulties are discussed.

Our thanks are due to Dr. M. Balasubramaniam, Principal of the Jawaharal Institute of Post-graduate Medical Education and Research, Pondicherry, for permitting us to publish this paper.

\section{References}

Chatterjee, B. M., and Sen, N. N. (i96o) Brit. J. Ophthal., 44, 440

CONSUl, B. N., KUlShrestha, O. P., and MEHROtRA, A. s. (1967) Ibid., 51, 65

CROMBIE, A. L. (1967) Ibid., 51, IOI

goodman, E. G., and IVerson, L. (1946) Amer. F. med. Sci., 21 r, 205

gupta, s. P., Agarwal, P. K., and Pratab, U. B. (1970) Orient. Arch. Ophthal., 8, 94

MATHUR, J. S., GUPTA, S. P., NEMA, H. V., and KATIYAR, G. P. (I970) Ibid., 8, I87

MORTADA, A. (1963) Amer. J. Ophthal., 55, 327

REESE, A. B., and GUY, L. (1933) Ibid., 16, 7 18 